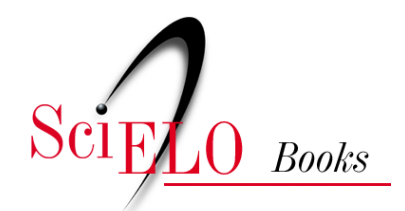

\title{
Prefácio \\ (Des)alinhando expectativas em torno de manuscritos e impressos alagoanos
}

\author{
José G. Gondra
}

\section{SciELO Books / SciELO Livros / SciELO Libros}

GONDRA, J.G. Prefácio: (Des)alinhando expectativas em torno de manuscritos e impressos alagoanos. In: SILVA, E.O.C., SANTOS, I.G. and ALBUQUERQUE, S.L., orgs. A história da educação em manuscritos, periódicos e compêndios do XIX e XX [online]. Rio de Janeiro: EdUERJ, 2018, pp. 15-23. ISBN 978-85-7511-483-4. https://doi.org/10.7476/9788575114834.0002.

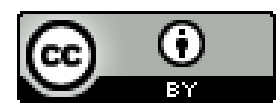

All the contents of this work, except where otherwise noted, is licensed under a Creative Commons Attribution 4.0 International license.

Todo o conteúdo deste trabalho, exceto quando houver ressalva, é publicado sob a licença Creative Commons Atribição $\underline{4.0}$.

Todo el contenido de esta obra, excepto donde se indique lo contrario, está bajo licencia de la licencia $\underline{\text { Creative Commons }}$ $\underline{\text { Reconocimento 4.0. }}$. 


\section{PREFÁCIO}

\section{(Des)alinhando expectativas em torno de manuscritos e impressos alagoanos}

José G. Gondra

Lançado em 2015, o filme Spotlight dá visibilidade às experiências ocorridas na cidade de Boston, em 2001. Trata-se de um tipo de drama biográfico dirigido por Tom McCarthy, no qual um grupo de jornalistas investiga casos de pedofilia praticados por padres católicos, acobertados pela cúpula da Igreja. Ao reunir e tratar de um importante conjunto documental, os jornalistas denunciam as violências cometidas e o envolvimento de líderes religiosos nas experiências descritas. Ao posicionar o espectador dentro da redação e no processo de investigação que realizam, o diretor assinala um modo de se praticar o jornalismo investigativo, chamando atenção para o que mobiliza aqueles profissionais na denúncia da hipocrisia, da burocracia e do abuso sobre os mais desfavorecidos. Indicado para seis categorias do Oscars na premiação de 2016, ganhou os prêmios de melhor filme e melhor roteiro original.

Em certo sentido, o presente livro, organizado por Edgleide de Oliveira Clemente da Silva, Ivanildo Gomes dos Santos e Suzana Lopes de Albuquerque, funciona como uma espécie de holofote sobre acontecimentos pouco conhecidos, sombreados por uma historiografia panorâmica, produzida, sobretudo, no sudeste do Brasil, que tem o mérito de transformar em nacional o que se processa nos planos estadual e regional. Desse modo, ao girarem a lente e reunirem seis 
estudos, os organizadores combinam um material que torna mais complexas as intrigas ou narrativas da história da educação brasileira.

$\mathrm{O}$ primeiro estudo oferece elementos importantes para se pensar a respeito da educação ofertada por não religiosos na região de Alagoas. A localização e o tratamento de fontes primárias pelos autores, até então desconhecidas no âmbito da historiografia da educação alagoana, dão a ver uma série de acontecimentos que permitem compreender as estratégias e possibilidades voltadas para a oferta de instrução nas Alagoas. Nessa espécie de genealogia das formas educativas, os autores reconhecem a existência de relações de poder que marcam a atuação de professores e da comunidade interessada na difusão das letras por parte de agentes não vinculados à hierarquia da Igreja Católica, a partir da segunda metade do século XVIII, na Vila de Alagoas.

$$
\text { viscipscio ixmitiketuat. }
$$

A Amrica du Norte apresenta neste momento uni facto, que se reproduz em todu o mundo, mas que passa desapercelido, isto $\dot{b}$ homens do poro, olliciaes de oflicio applicando ás letras, sciencias e arı es, âs disposiçóes que receberio da nalureza, fazerem-se celebres por seus conhecimentos, e preslarem serviços a humanidade apczar do seu cstado de officiacs de officio.

Elitu Burritt, nascido em 1811 no estado de Councticut, filto de um sapateiro, andou n'uma escola por tres mezes; porém as circumstaneias de seu pai o sapateiro obrigárăo Elihu Burritt a trabalhar de um officio, e como a sua natureza physica era muito robusta, entrou na oflicina de um ferreiro, e consagrava ao estudo os puucos instantes que lhe sobrávão. Sosinho, sem mestre algum, pela unica força da sua energica vontade, applicando assitn por intuiçăo os principios do Jacotismo, o ferreiro Burritt conseguiu apprender as mathematicas, o latim, o grego, o francez, o italiano, o allemão, o hespanhol: Já, sem o querer, o ferreiro tinha ganhado fama: offerecerão-lhe a direç̧ão de um col. legio; mas no fim de um anno alterou-se a sua saudo por causa da assiduidade que exigião uma vida tão sedentaria e os esforços de. estudo que tinha feito; voltou para a officina e a bigorna, e em breve ficou restabelecido. Pouco depois una casa de commercio the offerecen um emprego vantajoso; durante as viagens que fazia para os interesses da casa, apprendeu a lingua hebraica e escreveu o seu primeiro opusculo, o Tumulo do meu Irmão. 
O segundo estudo incide em uma temática muito cara para se pensar a problemática da instrução e das propriedades gerais do aparato escolar. Trata-se das mediações e disputas em torno do melhor e mais eficaz método de ensinar e de toda a utensilagem, indústria e comércio associados ao mesmo. Nesse caso, a autora elegeu e se debruçou sobre uma experiência extremamente instigante, pois coloca em xeque os mecanismos da colonização portuguesa em suas permanências com a complexa circulação de pessoas, matérias e modelos pedagógicos ao longo do século XIX. Com isso, ao eleger as proposições de Jacotot e suas apropriações no Brasil, a pesquisa ajuda a interrogar os interesses de uma pedagogia nos marcos da experiência portuguesa. Jacotot viveu no século XVIII, na França, e se tornou conhecido por ter elaborado uma proposta de método pautada na emancipação intelectual ${ }^{1}$. Jacotot formulou sua proposta a partir de uma experiência inusitada, quando se viu constrangido a ensinar francês para holandeses, em uma situação de dupla ignorância. Diante desse desafio, a partir de uma edição bilíngue do livro Telêmaco, percebeu que qualquer pessoa pode aprender sozinho e que o professor pode ensinar mesmo que ignore uma determinada matéria. $\mathrm{O}$ método apresenta quatro pilares: o primeiro afirma que todos os homens possuem igual inteligência; o segundo, que cada homem recebeu de Deus a faculdade de aprender sozinho; o terceiro, que podemos ensinar o que não sabemos; o último, que tudo está em tudo. Na avaliação de Jacotot, o conhecimento é um direito e todos podem adquiri-lo, sendo a disposição para aprender a exigência fundamental. Denominado método de educação universal, "esse método da igualdade era, antes de mais nada, um método da vontade. Podia-se aprender sozinho, e sem mestre explicador, quando se queria, pela tensão

1 Disponível em: http://memoria.bn.br/DocReader/docreader.aspx?bi$\mathrm{b}=730076$ \&pesq\%22pesq. Acesso em: 6 nov. 2017. 
do próprio desejo ou pelas contingências da situação" (Rancière, 2002). As proposições e seus princípios parecem ter sido objeto de uma difusão com algum grau de alcance na América $^{2}$, como pode ser observado no caso de Elihu Burrit, noticiado pelo Jornal Sciencia, de 1847 , na matéria seguinte a que noticia a criação do Instituto Panecástico do Brasil.

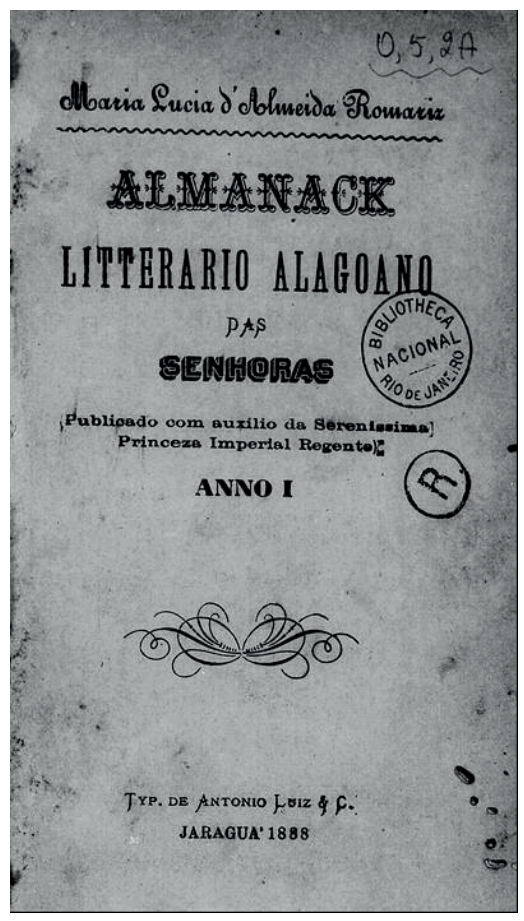

O terceiro estudo entrecruza elementos da história de professoras com a inserção pública do feminino em outros ambientes da vida pública. No caso, o jornalismo e a literatura. A autora explora

2 A respeito da circulação das proposições de Jacotot em outros países da América, cf. Kohan, 2013. 
os primeiros indícios da escrita literária de professores. Ao selecionar duas experiências de professoras-autoras, a pesquisa lança luzes e interrogações a respeito das trajetórias de Alcina Carolina Leite (1854-1939) e Maria Lucia d'Almeida Romariz (1863-1917) na escola provincial e na vida pública alagoana. Para tanto, a pesquisa focaliza o projeto de publicação do Almanack Litterario Alagoano das Senhoras ${ }^{3}$ (1888), publicado em Maceió, com auxílio da Sereníssima Princeza Imperial Regente, com a colaboração de nomes da literatura brasileira feminina, entre as quais, a baiana Ana Autran, a pernambucana Francisca Izidora, as cearenses Francisca Clotilde e Alba Valdez, as gaúchas Cândida Fortese Senhorinha Chaves, a paraibana Anna Ribeiro e as sergipanas Maria Cândida Ribeiro e Maria Minervina de Menezes. De acordo com o estudo, apesar da condição feminina desfavorável em ambas as posições, as respectivas trajetórias foram de algum modo protegidas dos estigmas da época, considerando a projeção das duas professoras no universo literário nacional e internacional. Os versos contidos, que anunciavam uma vida silenciada e subjugada à figura masculina, não condiziam com o fato de terem se insurgido como figuras singulares em um cenário que inibia o exercício da intelectualidade feminina.

O quarto estudo incide sobre a trajetória de um sujeito poliédrico e um polígrafo, com foco em uma de suas intervenções no campo da educação, isto é, a produção de livros destinada ao universo escolar. Trata-se de um homem que ocupou posições sucessivas e simultâneas no campo médico, pedagógico, da gestão, da política e da literatura: Thomaz do Bomfim Espindola (1832-89). A produção intelectual desse autor recobre campos disciplinares diversos, tendo produzido na área da Medicina e da Educação, a

3 Disponível em: http://memoria.bn.br/DOCREADER/docreader.aspx?$\mathrm{BIB}=707260$. Acesso em: 06 nov. 2017. 
citar: Profilaxia do "colera morbus" epidemico: sintomas, tratamento curativo desta molestia, dieta, convalescencia, consideraçóes gerais e clinicas (Ceará, 1862); Relatório da Instrução Publica e Particular da Província das Alagoas (1866, 1867 e 1868), escrito durante a ocupação do cargo de Diretor Geral de Estudos, em cujo conteúdo faz um levantamento da situação escolar de Alagoas dos anos de 1835 a 1865 . Há também a obra geográfica Geografia alagoana ou descrição fisica, politica, historica da provincia das Alagoas, publicada em duas edições (1860 e 1871). De acordo com a pesquisa realizada, o livro Elementos de Geografia e Cosmografia oferecido à mocidade alagoana (1885) ampara-se em alguns referenciais utilizados nos principais colégios europeus. Desse modo, a terceira edição deste livro é descrita como "a mais correcta e de accordo com os progressos da ciência”. O saber geográfico procurava cumprir a dupla função de mensurar e absolutizar. A mensuração ou demarcação deveria constar nas escolas, a fim de preparar os sujeitos para conhecerem e zelarem pela integridade geográfica do país. A segunda função visava a colocar a ciência geográfica como modeladora das demais, posto que se autorrepresentava como uma "ciência das evidências", equivalente, portanto, à racionalidade que tinha como objeto os elementos físicos e naturais, pautada na observação, na descrição e na experimentação.

O penúltimo estudo incide igualmente sobre outro personagem alagoano poliédrico e polígrafo. Trata-se, nesse caso, de Arthur Ramos (1903-49). Filho de médico e formado em Medicina pela Faculdade da Bahia, em 1926, na curta vida, deixou um legado de mais de seiscentas obras, entre livros e artigos, que até hoje são fontes para a psiquiatria, o negro, o índio e o folclore brasileiro. Esse estudo procura refletir a respeito da compreensão de Arthur Ramos em relação à cultura negra e seu valor na constituição e formação do negro. Para a autora, os estudos de Arthur Ramos sobre as relações da cultura negra com a educação devem levar em consideração os limites e possibilidades de sua época, contribuin- 
do para revogar a tese da inferioridade biológica do negro. No entanto, advoga que Ramos também contribuiu para a permanência da tese da inferioridade cultural das populaçóes que não tinham acesso ao saber letrado. Para ele, os grupos considerados atrasados culturalmente apenas evoluiriam por meio da educação escolar, considerada pelos intelectuais como chave para se alcançar o progresso e a civilização do país. Mas não qualquer educação. Esta deveria estar pautada em postulados e procedimentos médico-higiênicos, como os que teve oportunidade de executar ao ser convidado por Anísio Teixeira para chefiar o Serviço de Ortofrenia e Higiene Mental-SOHM (1934-39). Na direção do SOHM, o médico alagoano analisou mais de 2000 estudantes de escolas públicas do Rio de Janeiro, buscando romper com algumas concepções que rotulavam crianças como "anormais" por apresentarem comportamentos tidos como inadequados, tais como desatenção, rebeldia e mentira, entre outros. Defendia que os comportamentos não estavam associados a uma matriz genética, mas, sobretudo, social. Assim, comprovou no referido serviço que a maior parte dos comportamentos tidos como indesejáveis decorria de situações sociais na casa e na escola. Desse modo, minimizou a questão racial, biológica e genética, acentuando o papel das condições na constituição das condutas e comportamentos dos sujeitos.

O último estudo recobre o tema da infância, tomando como fonte uma revista pedagógica. A autora opera com a Revista de Ensino ${ }^{4}$, veículo oficial da Diretoria Geral da Instrução Pública de Alagoas, criada em 1925, tornando-se, posteriormente, periódico de divulgação da Sociedade Alagoana de Educação, a partir de 1930 .

4 Disponível em: http://memoria.bn.br/DocReader/docreader.aspx?bi$\mathrm{b}=761559$ \&pasta $=$ ano\%20192\&pesq $=$. Acesso em: 15 maio 2018 . 


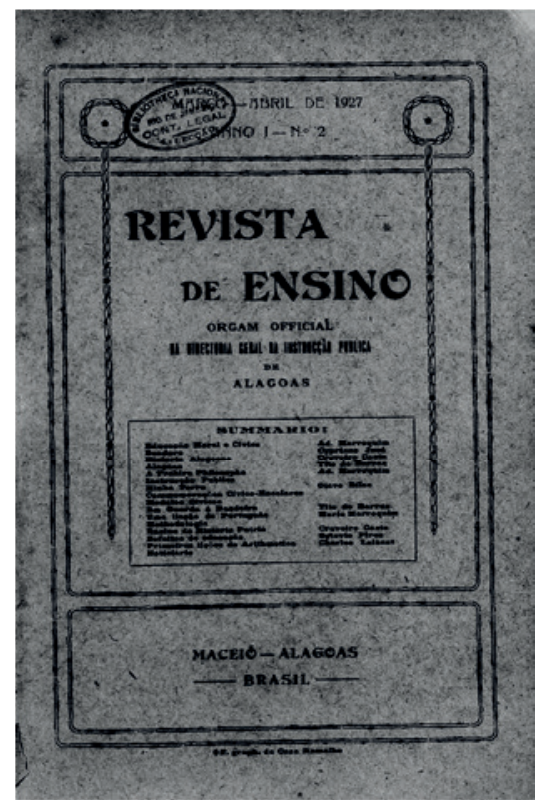

De acordo com a pesquisa, o impresso em questão passou a ser um meio de fornecer informação aos professores e divulgar os novos processos de ensino, já que eram publicados planos de aula, ensaios de professores da Escola Normal de Maceió, do Liceu Alagoano, dos Grupos Escolares da capital e trabalhos de autores do Brasil e do exterior, focalizando temas relacionados à chamada Escola Nova. Para a autora, uma parcela significativa das representações de infância difundidas pela Revista de Ensino alagoana partia de uma visão ativa, progressiva e, ao mesmo tempo, isolada e individual dessa "etapa” da vida. Os adjetivos atribuídos à infância como um tempo de imitação, fantasia e vivacidade representam uma maneira de enxergar a criança como um ser atuante na construção de um novo tempo e modelável aos objetivos culturais impostos, que, no Brasil, de acordo com argumentos da autora, fo- 
ram fundamentados teoricamente por John Dewey nos debates educacionais promovidos a respeito da Escola Nova.

Por fim, os seis estudos reunidos neste livro de forma meticulosa mobilizam problemas e documentação relevantes para o campo da história da educação. Este tipo de investimento contribui para romper com duas inércias que dominaram o campo da história da educação até os anos 1990. A primeira corresponde a um tipo de narrativa centrada em experiências desenvolvidas nos polos centrais do poder, que assumiam caráter generalizante, nacional. A outra se encontra correlacionada com a inércia dos arquivos. Neste livro, os leitores são provocados e instigados a lidar com coleções e gêneros de documentos bastante peculiares, recobrindo manuscritos, jornais científicos e literários, compêndios e revistas especializadas. Provocação que (re)introduz o leitor em problemáticas de vários presentes, como a da profissionalização do ofício docente, aparecimento da escola, representações da infância, (re)invenção de modos de ensinar, disciplinarização de saberes e participação feminina na cena pública. Organizados sob um alinhamento temporal, os capítulos desalinham percepções consagradas na e pela historiografia da educação ao explicitarem a existência de redes complexas de relações de saber, poder e de agenciamentos empenhados em construir uma escola e uma pedagogia científicas nas Alagoas, parte do Brasil a ser lembrada ou iluminada, tarefa bem cumprida por este livro que, ao fim e ao cabo, funciona como um spotlight.

\section{Referências}

KOHAN, Walter. O mestre inventor. Belo Horizonte: Autêntica, 2013.

RANCIÈRE, Jacques. O mestre ignorante: cinco lições sobre a emancipação intelectual. Belo Horizonte: Autêntica, 2002. 